\title{
CIDADE E SUSTENTABILIDADE TERRITORIAL
}

\author{
city and territorial sustainability
}

Norberto Nuno Pinto dos Santos*

\section{Resumo}

O conceito de sustentabilidade territorial está cada vez mais presente nas agendas locais de intervenção e ordenamento do território. A sua importância expressa-se na organização de redes de instituições e cidades, assim se obtendo vantagens com as relações e experiências conjuntas. Dando especial atenção à coesão territorial perspectivada através da gestão urbana, da integração política, da reflexão ecossistémica e da cooperação e parceria, neste texto valoriza-se a qualidade de vida da população no âmbito do desenvolvimento urbano sustentável.

Palavras-chave: Sustentabilidade territorial, Ordenamento do território, Gestão urbana.

\begin{abstract}
The territorial sustainability is increasingly present in local agendas for action and planning. This importance is expressed in the organization of networks of institutions and cities, in order to get advantages from the relationships and shared experiences. Paying particular attention to territorial cohesion envisaged by the urban management, policy integration, the ecosystemic reflection, cooperation and partnership, in this text we value the quality of life in the context of sustainable urban development.

Key words: Territorial sustainability, Planning, Urban management.
\end{abstract}

\section{Résumé}

La question de la durabilité des territoires est de plus en plus présente aux programmes locaux d'action et d'aménagement du territoire. Son importance se traduit dans l'organisation de réseaux d'institutions et de villes par lesquelles on obtient les avantages associés au partage d'expériences. Faisant attention à la cohésion territoriale, envisagée à travers la gestion urbaine, l'intégration politique, la réflexion écosystémique et la coopération et le partenariat, ce texte met en relief l'importance de la qualité de vie des gens au cadre du développement urbain durable.

Mots-clés: Durabilité des territoires, Aménagement du territoire, Gestion urbaine.

(*) Prof. Dr. do Centro de Estudos de Geografia e Ordenamento do Território, Centro de Estudos de Geografia e Ordenamento do Território, Departamento de Geografia, Universidade de Coimbra, CEP: 3004-530, Coimbra - Portugal, Tél: (239) 857000 - norgeo@ci.uc.pt 


\section{INTRODUÇÃO}

Tal como nos dias de hoje, os Ensaio sobre o princípio da população (1798 e 1803), de Robert Malthus, surgem num período de grandes transformações socioeconómicas, na altura associadas ao pós Revolução Francesa, comparável à actual globalização socioeconómica enquanto ignitora ideológica, motivadora de transformações e com uma forte capacidade publicitária .

A população humana tende a crescer para além das possibilidades de o meio a sustentar, com o crescimento exponencial daquela a ser acompanhado pela progressão aritmética da produção de recursos alimentares. Se factores externos como doenças e falta de alimento (efeitos positivos na teoria de Malthus), não limitassem o crescimento da população humana, os meios de subsistência não teriam um aumento equivalente ao que era necessário para alimentar a população (com duplicação a cada 25 anos ou menos ainda), assumindo que a miséria do mundo dependia do aumento da população

Perante esta situação e para evitar uma catástrofe, Malthus propôs uma restrição moral aos nascimentos, o que significaria proibir o casamento entre pessoas muito jovens (prolongamento do celibato), limitar o número de filhos entre as populações mais pobres (obstáculos preventivos de redução da natalidade - contracepção e aborto), elevar o preço das mercadorias e reduzir os salários, a fim de pressionar os mais humildes a ter uma prole menos numerosa.

Algumas das orientações de Malthus são hoje seguidas por uma parte significativa da população, embora tendo por base motivações diversas, mas a similitude deste cenário com aquele que nos é descrito pelos defensores do exaurir dos recursos naturais do planeta é assustadoramente coincidente.

A teoria da Pegada Ecológica é disso um exemplo concreto. Sabemos hoje que estamos a consumir recursos acima do que seria adequado para assegurar a sobrevivência da população de um futuro não muito distante. Esta imagem, em tudo semelhante à que nos foi legada por Malthus, evidencia que o capital natural de um futuro próximo depende de uma mudança significativa dos níveis de consumo e da actuação adequada para com o ambiente.

Esta sobreexploração dos recursos do planeta é da responsabilidade do estilo de vida das populações do mundo desenvolvido, do desajustamento das suas políticas e da subvalorização da educação ambiental dos cidadãos, que resulta numa consciencialização tácita (tendencialmente reactiva) que precisa de ser substituída, rapidamente, por uma intervenção pro-activa.

Os dados da Ecological Footprint Organization - Redefining Progress (http://www.ecologicalfootprint.org/) são disso elucidativos (Figura 1). Efectivamente, quando se espacializa o excesso de consumo de natureza relativamente aos níveis de consumo médio que não deveriam ser ultrapassados, são os centros dos arquipélagos económicos (EUA, Japão e Europa), conjuntamente com os países produtores de petróleo e o turismo massificado, que detêm o maior deficit no contributo para a preservação do capital natural do nosso planeta.

Todavia, os países em vias de desenvolvimento parecem querer chegar, muito rapidamente, a valores similares àqueles, quantas vezes por influência perversa das economias centrais.

As áreas urbanas têm uma importância decisiva na avaliação da pegada ecológica, já que são os estilos de vida das populações urbanas que revelam maiores níveis de consumo e acções mais agressivas para a natureza. Nos últimos anos as grandes cidades ou megalópoles deixaram de estar predominantemente no mundo desenvolvido e passaram a ter nos países em vias de desenvolvimento um crescimento exponencial: de população, de consumo de recursos, de agressões ambientais, associada a uma forma pouco distributiva e frequentemente muito injusta de partilha de riqueza. Um estudo publicado pela ONU - UN-HABITAT deixa claro que, nos próximos anos, serão as grandes cidades do Mundo em vias de desenvolvimento que verão surgir grandes megalópoles de mais de vinte milhões de habitantes (http://www.pime.org.br/mundoemissao/estatisticasmundo2.htm).

Os impactes destas concentrações de população podem ser verdadeiramente catastróficos. Verdadeiras centrais de consumo de recursos são as principais responsáveis pelo aquecimento global, pelo consumo de madeira, de água e energia, sabendo que, mesmo com situações ideais, estes 


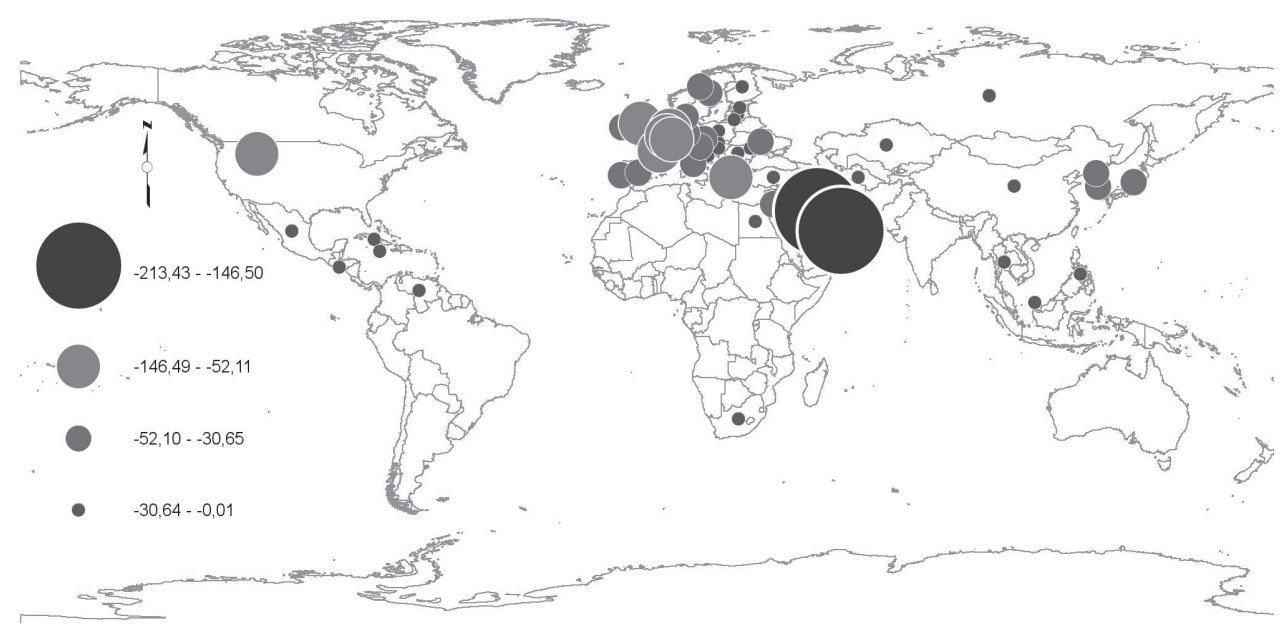

Figura 1 - Países com Balanço Ecológico negativo

(Pegada Ecológica mais Capacidade Biológica). Em hectares globais

Fonte: Ecological Footprint Organization - Redefining Progress

aglomerados estão sempre à beira do colapso. Isto sucede devido aos valores implicados nos níveis médios de fornecimento de bens e serviços à população e devido ao pouco que é necessário para interromper estes fluxos continuados de bens e de resíduos, quer por eventual colapso das infra-estruturas, quer por intervenção criminosa ou terrorista ou, ainda, por acção da natureza.

A situação em Portugal, em termos urbanos, não apresenta a dimensão que é encontrada noutras áreas do planeta. Todavia, importa salientar alguns aspectos significativos, que são motivo para caracterizar a qualidade de vida da população.

O crescimento da população urbana, em Portugal, é uma evidência. Se na década de setenta foram elevadas a cidade 5 localidades, que se juntaram às 40 que existiam até então, as décadas seguintes foram responsáveis pelo aparecimento de 81 novas cidades (34 na década de 1980 e 47 na de 1990), que com as 25 cidades que surgiram já neste século, dão a Portugal uma rede urbana de algum significado quantitativo.. Todavia, em termos qualitativos (acesso a serviços, aquisição de bens, acessibilidade, justiça distributiva), esse significado apresenta-se díspar, tal como sucede quando se compara a densidade relacional das diversas cidades.

As 151 cidades portuguesas (desde 2005) integram 4 milhões de pessoas, $40 \%$ da população total em 2001, correspondendo a $2 \%$ do território nacional, com uma densidade média de 2.200 hab/Km2, quase vinte vezes mais do que a média nacional. Metade da população urbana vive em 14 cidades com mais de 50 mil habitantes, oito delas têm mais de 100 mil habitantes (Lisboa, Porto, Gaia, Amadora, Braga, Almada, Coimbra e Funchal) e, com ficou dito, existe uma enorme disparidade de dimensão populacional das diversas cidades. A mais populosa é Lisboa, com 564 657 habitantes, e a com menor quantitativo populacional é Santana, com 1336 habitantes.

Como é óbvio, estas diferenças em nada ajudam na procura de um desenvolvimento equilibrado, mas quando se fala da sustentabilidade destas localidades, muitas vezes a dimensão média ganha significado e as pequenas cidades começam a apresentar alguns trunfos que nos fazem pensar no modo como Ebenezer Howard interpretava a relação entre cidade e espaço envolvente, a que adiante se fará referência.

As dinâmicas populacionais sofreram alterações significativas durante o século XX. O aumento da rede urbana, não foi, de facto, motivo de harmonização territorial. Como refere Ferrão (2005), o avolumar de diferenças entre o litoral e o interior, expresso pela atractividade do litoral perante a repulsividade ou concentração populacional do interior, resulta numa valorização dos centros em detrimento dos quantitativos populacionais dos territórios envolventes. 
O tema que aqui é proposto associa dois conceitos centrais da socioeconomia contemporânea - Cidade e Sustentabilidade.

A cidade é responsável pela organização espacial de uma sociedade crescentemente dependente do poder de um mercado neoliberal que dá valor a percepções globais, mas que depende das actuações locais de agentes que precisam de estar bem preparados e apoiados em estruturas de relação bem sustentadas.

A situação das cidades portuguesas inscreve-se naquela que apresentam, grosso-modo, as cidades da União Europeia. É perceptível que a hierarquia urbana tem estado sujeita a mutações significativas. Isto sucede porque solicitações muito diversificadas arvoram a cidade para intervenções cada vez mais importantes ao nível da oferta de qualidade de vida à sua população e àquela que fica ao alcance de um marketing territorial crescentemente cativante e concorrencial. É nesta abordagem, de capacidade de influência em áreas e esferas de actuação muito amplas, que a sustentabilidade veiculada pelas cidades ganha importância.

A população do mundo desenvolvido está mais desperta para a importância de garantir aos seus descendentes a possibilidade de viverem em simbiose com o espaço de que fazem uso, interpretando relações de integração entre o homem e a natureza.

A flexibilização, a reciprocidade, a solidariedade, a qualificação, o respeito pela alteridade, a responsabilidade, ganham terreno nas políticas de intervenção pública e ordenamento do território, assumindo que o crescer primeiro para distribuir depois está desajustado perante o distribuir para crescer.

O homem parece ter-se ajustado a esta realidade através de camuflagens diversas, que assume perante as esferas de acção em que participa. Isto sucede porque ele sofre grandes influências externas e uma acção de pressões diversas sobre a decisão que são cumulativas com a informação desmedida que condiciona as opções. Deste modo, surge uma racionalidade limitada que caracteriza a relação entre o homem e a informação disponível, porque, de facto, não é possível dispor, em todos os momentos, de todas as informações necessárias para fazer a melhor escolha e procurar obtê-las pode ser custoso em tempo e dinheiro. Assim, podemos cometer erros, dado que ser racional não significa ser infalível, mas, antes, ser capaz de tirar ensinamentos dos erros (BIMONT, 1996: 13).

É nesta perspectiva que a cidade sustentável tem que ser entendida. É um instrumento de intervenção social e política que é preciso aprender a utilizar, sabendo que teremos sempre que lidar com processos que lesam o ambiente, mas que devemos intervencionar de modo a tornar os seus impactes compagináveis com o propósito da qualidade de vida e da sua sustentabilidade.

\section{A COESÃO TERRITORIAL E O DESENVOLVIMENTO URBANO}

A Cooperação Europeia nos Domínios da Coesão Territorial e do Desenvolvimento Urbano foi um passo fundamental para o desenvolvimento de políticas orientadoras de comportamentos

As questões referentes à sustentabilidade urbana têm que, forçosamente, tomar em atenção o território e as relações que se estabelecem entre as diversas componentes que nele se amalgamam. Como refere Meo (1998) o território envolve o estudo do espaço, entendido como uma geografia da participação socioeconómica das populações; a política, por intermédio do controlo dos agentes reguladores que assim promovem o ordenamento, com base em formas diversas de planeamento, estando o urbanismo comercial a evidenciar-se pertinente nas temáticas das cidades sustentáveis; e a identidade, que tem no desenvolvimento de um sentimento de pertença uma das referências principais da cidade na relação com o espaço envolvente, entendido como área de influência.

Por isso mesmo a coesão territorial, assumida pelas Estratégias de Lisboa (2000) e de Gotemburgo (2004), foi entendida como fundamental para o processo de valorização sustentável dos espaços urbanos. A Agenda Territorial da União Europeia, que surge associada à Carta de Leipzig para as Cidades Europeias Sustentáveis, é um "quadro de referência para a acção política, orientado para contribuir para o desenvolvimento económico sustentável e para a criação de emprego, bem 
como para o desenvolvimento social e ambiental" (Fórum do Urbanismo - Cooperação Europeia nos domínios da Coesão Territorial e do Desenvolvimento Urbano).

Esta valorização da qualificação do território surge no Quadro de Referência Estratégico Nacional (2007-2013) quando se afirma a sua importância na atractividade e na potenciação dos factores de progresso específicos de cada região, contribuindo para o desenvolvimento sustentável e regionalmente equilibrado de todo o país (QREN, 2007-2013). Assim, sendo o desenvolvimento sustentado das regiões (e sabemos bem que funcionalmente estas regiões são lideradas por uma cidade ou cidades que influenciam de modo decisivo a sua caracterização) ancora-se em factores endógenos e inimitáveis dos territórios, que são garantia de coesão socioeconómica a médio e longo prazo. Entre os factores endógenos e inimitáveis estão, para além dos ex-libris patrimoniais, da funcionalidade económica e das potencialidades dos serviços existentes, a imagem da sustentabilidade da cidade e, com certeza, a sua sustentabilidade efectiva, que condiciona a fixação de população.

Neste âmbito o Grupo de Peritos sobre o Ambiente Urbano da Comissão Europeia, que criou em 1993 o projecto Cidades Sustentáveis, define claramente que os níveis de actuação não podem incidir somente "nas cidades, mas em todos os níveis da hierarquia urbana" (COMISSÃO EUROPEIA, DIRECÇÃO GERAL XI, 1996), identificando os princípios que devem ser tomados em atenção para a sustentabilidade nas zonas urbanas:

A gestão urbana é muito relevante. Associado ao planeamento, este princípio utiliza instrumentos valorativos das dimensões ecológica, social e económica e assume uma abordagem integrada de grande poder de actuação, mas cujas políticas e metodologias não vamos desenvolver de forma exaustiva, mas de que falaremos mais à frente.

Um segundo aspecto é o da integração política. Procurando o concertar de acções, propõem-se situações de subsidiariedade e de responsabilização das diversas partes, de modo a que daí resultem situações de sinergia que beneficiem os intervenientes. Salienta-se assim, a importância do estabelecimento de relações em rede com os territórios de diferentes níveis hierárquicos. Ocorrem mudanças ao nível político-institucional e ao nível da organização económica, sabendo que cada um dos territórios pode, se o sistema funcionar, tirar vantagens e exponenciar oportunidades, que põem em causa a organização rígida do modelo hierárquico que se centra na capital nacional. Ganha significado a teoria de Ascher (1998) do efeito de túnel, mostrando que complementaridades e sinergias, no sentido da inovação, são incontornáveis na organização política do espaço. A crise das hierarquias dá expressão à crise do Fordismo, e faz surgir formas mais flexíveis, com adaptação mais rápida, de pensar o território e do seu funcionamento, tornando imprescindível a emergência do conceito de rede associado ao planeamento estratégico e ao planeamento participativo.

Como refere Camagni (1992) há uma sobreposição entre a hierarquia tradicional dos centros e uma hierarquia de redes. Identifica-se uma rede de primeiro nível integrando as cidades mundiais que tem processo de sinergia na gestão das relações financeiras, diplomáticas, de informação e de controlo; estabelece-se uma rede secundária de cidades nacionais especializadas que procuram partes do mercado internacional em sectores especializados; ganha importância um terceiro nível de cidades regionais especializadas que visam ir para além do meio local.

Esta abordagem global/local ao estruturar uma actuação integrada horizontalmente de modos complementar e/ou sinergético/inovador permite a implementação de estratégias comuns que são fundamentais no processo de promoção da sustentabilidade urbana.

Em terceiro lugar importa salientar a reflexão ecossistémica. Entendendo a cidade como um sistema complexo, importa potenciar a relação entre o mundo natural e o mundo social, entendidos como partes de um todo, onde a energia, os fluxos e os resíduos detêm um papel fundamental. Embora esta abordagem encontre pontos de contacto com momentos de discussão sobre a cidade do princípio do século XX, o seu valor para a sustentabilidade é de grande relevância. A preservação dos ecossistemas é fundamental, mas no que ao urbano diz respeito, a avaliação precisa de ser exploratória, de modo a permitir a minimização de impactes resultantes de actuações menos consentâneas com os pressupostos da sustentabilidade urbana. Daí que as propostas tenham que surgir 
dando expressão à manutenção das valências geradoras de qualidade de vida, ao restabelecimento de equilíbrios afectados, importantes para a preservação e sustentabilidade, à necessidade de ordenamento territorial, ao reciclar de processos não estratégicos, ao desmantelamento de outros por desqualificação ambiental. Esta ideia encontra-se precisamente em Andrade (2003) que afirma que "o conceito de desenvolvimento urbano sustentável passa por uma estratégia de ecologia urbana que coloca a cidade como um meio ambiente construído não apenas como usuário do ambiente natural, mas também como fontes de recurso. De acordo com esta visão, os aglomerados urbanos deveriam ser analisados como ecossistemas complexos, embora com um metabolismo mais intenso, onde o metabolismo urbano deve ser analisado como um intercâmbio de matéria, energia e informação entre o assentamento urbano e seu contexto geográfico".

Refira-se, contudo, que já a Escola de Chicago e, antes dela Ebenezer Howard, nos tinha proposto valorizações suportadas por princípios de sustentabilidade para os territórios urbanos logo no final do século XIX e princípio do século XX, tendo Bourniville e Port Sunlight, construídas pelos industriais de chocolate, George Cadbury, e da produção de sabão, William Hesketh Lever, respectivamente, servido de referência a Howard, ao proporcionarem melhores condições de vida aos trabalhadores das suas fábricas e a outros que passaram a residir nessas cidades industriais.

Para os ecologistas urbanos a cidade constituía um aglomerado de um grande número de pequenas comunidades, denominadas áreas naturais (LEIDENBERGER, 2000). Esta organização surge como resposta a uma imigração dominante, falta de infra-estruturas e de habitação, iniciada por Robert Park num movimento que tomará o nome de Escola de Chicago. A sua empiria, criticada por muitos, é iniciadora dos estudos de diferenciação social do espaço urbano. Por exemplo Burgess "aplica ao estudo das comunidades o mesmo esquema teórico que se aplica à ecologia vegetal e animal" referindo "a existência de uma luta pelo espaço servindo-se de factores ecológicos e biológicos e utilizando os termos de invasão (de espaços por diferentes estratos sociais), competição (entre invasores e invadidos), domínio, sucessão e simbiose (SANTOS, 2005, p. 66)

Recuando até Ebenezer Howard, ele oferece-nos a Cidade Jardim. Os princípios que norteiam o pensamento de Howard são a rejeição da forma temporária e transitória do subúrbio, entendendo que o alívio do congestionamento não dependia do alargamento das áreas suburbanas, como se verificava até então, mas da descentralização de todas as suas funções" (SANTOS, 2005, p. 45) que nos oferece em To-morrow, a Peaceful Path to Real reforma, procurando a redução das densidades populacionais e o acréscimo de espaço verdes. Após a primeira guerra mundial, o movimento de Cidades-Jardim tornou-se um movimento de planeamento de novas cidades para a reconstrução na Inglaterra, onde predominam os princípios de desenvolvimento urbano sustentável através do tamanho controlado com acessibilidade aos espaços verdes e pedonais, transporte público adequado, reaproveitamento de resíduos sólidos em terras agrícolas e centros comerciais com economia local

"Uma das grandes críticas ao modelo de Cidade-Jardim sob o ponto de vista da sustentabilidade é o efeito da suburbanização que este causou, ou seja, a expansão urbana com baixas densidades que ocupam terras agricultáveis" (ANDRADE, 2003). O pressuposto de Howard da relação cidade/ espaço envolvente ajusta-se ao propósito actual de sustentabilidade, sendo contudo importante dar expressão à redução da Pegada Ecológica, especialmente nas sociedades desenvolvidas, de modo a tratar o espaço como um território com relações associadas a esferas de actuação (espaços de vida e espaços vividos) e a espaço de regulação (ordenamento) no sentido da valorização da qualidade de vida e preservação da paisagem numa perspectiva ecológica.

A abordagem de Howard era acompanhada pelo conceito de limite natural de crescimento, que implicava a limitação da dimensão da cidade, entre número de habitantes e densidade habitacional. Este conceito implicaria a criação de cidades satélites, a pequena distância da já existente, que integrariam a população excedentária em termos de limite natural de crescimento. Assim teríamos uma cidade com as mesmas características da cidade principal, embora mais pequena e com níveis 
de acessibilidade elevados entre si, podem resultar numa aglomeração urbana que, constituindo uma só comunidade, assume uma situação de integração funcional e espacial com o propósito de dar mais qualidade à vida urbana.

É interessante referir que Coimbra, nos anos (19)40, com Etiènne de Groer, teve projectado um modelo de cidade-jardim (Figura 2), intitulado Ante-projecto de urbanização e embelezamento e de extensão da cidade de Coimbra, que envolvia a cidade com "uma zona rural delimitada por uma circunferência com cinco quilómetros de raio, com o centro localizado no claustro de Santa Cruz" (SANTOS, 1983: p. 35). Procura-se valorizar a relação com a envolvente urbana, identificando lugares que se constituíam como níveis urbanos de $2^{\circ}$ nível, um relação com os espaços periféricos da cidade principal e a integração de espaços verdes no seio da área construída.

Aliás, a cidade apresenta, ainda hoje, uma mancha de espaços verdes interiores que lhe dão um valor de qualidade de vida que não pode ser menosprezada.

Outro aspecto importante é o da cooperação e parceria. Se bem que a cooperação e parceria sejam fundamentais ao nível institucional, importa sublinhar que também a democracia e planeamento participativos podem ter um papel fundamental no sentido da valorização da sustentabilidade. A percepção das populações e instituições (stakeholders) é fundamental para melhor compreender os problemas e ajustar os planos.

Como se refere no documento das Cidades Europeias Sustentáveis "a sustentabilidade é uma responsabilidade partilhada e a gestão sustentável é um processo de aprendizagem”, sabendo nós o quanto importante é o conhecimento e o contacto com as realidades para a tomada de decisão, no sentido da adopção ou da não adopção.

Assim, os instrumentos que permitem organizar e definir a actuação territorial, desde o âmbito nacional até ao âmbito local são muito diversos (o programa nacional da política de ordenamento do território (PNPOT); os planos sectoriais com incidência territorial (PSIT); os planos especiais de ordenamento do território (PEOT), compreendendo os planos de ordenamento de áreas protegidas (POAP), os planos de ordenamento de albufeiras de águas públicas (POAAP), os planos de ordenamento da orla costeira (POOC) e os planos de ordenamento dos parques arqueológicos (POPA), os planos regionais de ordenamento do território (PROT), os planos intermunicipais de ordenamento do território (PIOT); os planos municipais de ordenamento do território (PMOT), que compreendem os planos directores municipais (PDM), os planos de urbanização (PU) e os planos de pormenor (PP) (DGOTDU). Todavia, precisam de tomar em consideração a percepção das empresas, organizações, instituições e populações, como defende a Agenda 21 Local.

A qualidade de vida urbana é uma questão central quando nos referimos à sustentabilidade da cidade. Para que as medidas e acções que conduzem a resultados positivos sejam adequados à realidade dos territórios em questão, tem todo o significado identificar, através de formas de representação diversas, qual a percepção das populações envolvidas em relação às questões concretas que se pretendem ver resolvidas.

A valorização da participação das partes, com os decisores a tomarem conhecimento das vontades expressas pela população, é fundamental na procura da sustentabilidade, com o intuito de criar um futuro comum.

\section{O NOSSO FUTURO COMUM}

Quando a sustentabilidade não é atingida surgem situações de perigosidade, susceptibilidade e vulnerabilidade para as populações que é preciso tomar em especial atenção, porque podem resultar em rupturas que tenham impactes, de tal modo gravosos, que se tornem em situações de não retorno. O Relatório Brundtland referiu a importância das questões relativas aos recursos naturais e ambiente, mas hoje essas questões envolvem também referências sociais e económicas específicas das populações envolvidas e das que integram, mais tarde ou mais cedo, o sistema que está a ser motivo de análise. 


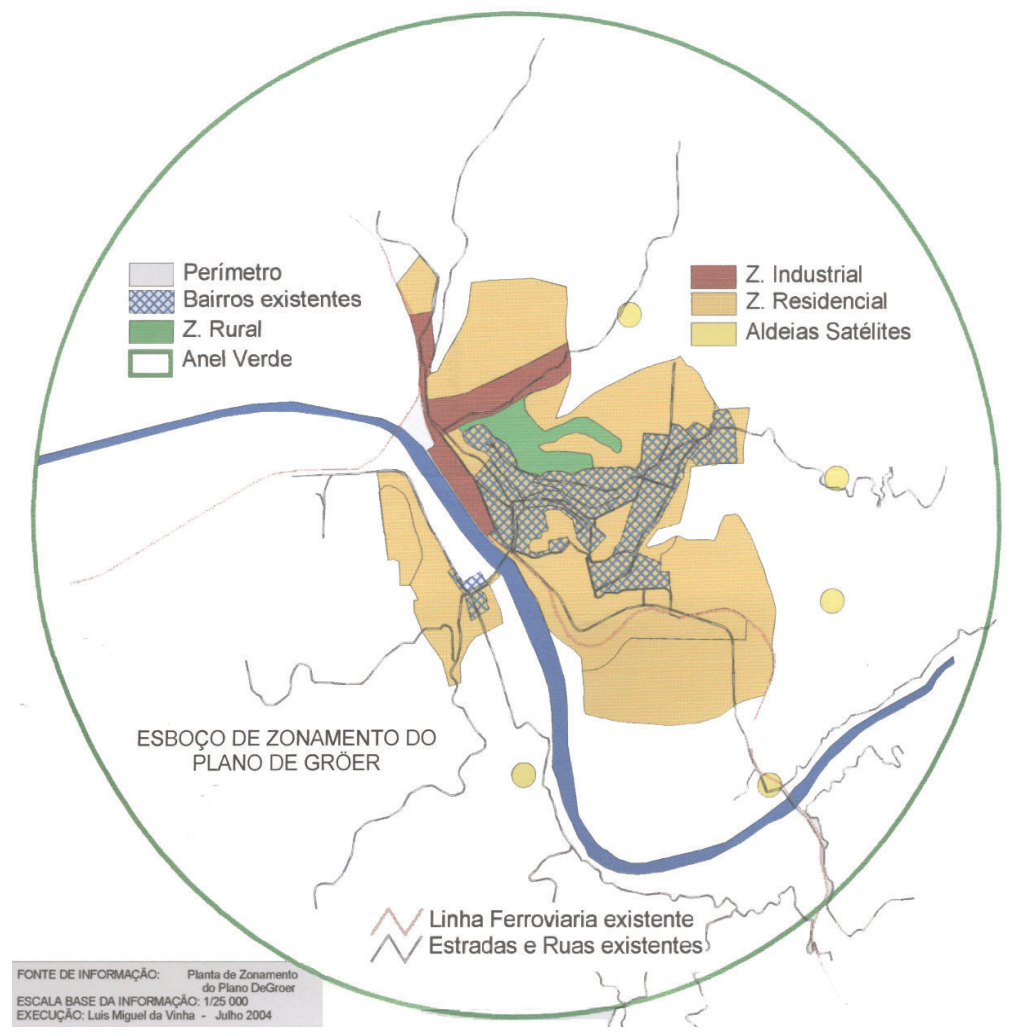

Figura 2 - Ante-projecto de urbanização e embelezamento e de extensão da cidade de Coimbra Fonte: Planta de Zonamento do Palno DeGroer. Luís Vinha

Em 1987 o Relatório “O Nosso Futuro Comum”, alertava o mundo para a necessidade urgente de alterar o desenvolvimento económico em direcção à sustentabilidade, com um menor impacte nos recursos naturais e no ambiente. Quer dizer, desenvolver no sentido da satisfação das necessidades presentes, sem deixar de tomar em consideração as necessidades das gerações futuras.

O Relatório Brundtland destacava três dimensões fundamentais do desenvolvimento sustentável: protecção ambiental, crescimento económico e equidade social, salientando a incompatibilidade entre desenvolvimento sustentável e os padrões de produção e consumo vigentes (http://www.unica. com.br/pages/sociedade_desenvolv2.asp)

Elaborado pela Comissão Mundial sobre o Meio Ambiente e Desenvolvimento das Nações Unidas, faz parte de uma série de iniciativas, anteriores à Agenda 21, que reafirmam uma visão crítica do modelo de desenvolvimento adoptado pelos países industrializados e promovido pelo $1^{\circ}$ Mundo, evidenciando a existência de uma sociedade em que o risco está latente e é continuado. Isto sucede devido ao uso excessivo de recursos naturais sem tomar em consideração a capacidade de suporte dos ecossistemas - a sustentabilidade.

A cooperação e parceria acima referidas encontram eco nas Iniciativas das Autoridades Locais em Apoio à Agenda 21 (Conferência das Nações Unidas sobre o Meio ambiente e Desenvolvimento) (Rio de Janeiro, Junho de 1992) onde as actividades valorizam, claramente, o processo de parceria e cooperação, tornando-se evidente a sua importância para a sustentabilidade e, de forma concreta, para a especificidade dos lugares que tem mais responsabilidade na organização espacial na contemporaneidade.

Estas questões expressam-se, quase sempre, através de indicadores de qualidade de vida para as populações. Parametrizando a leitura dos territórios definem características intrínsecas que constituem uma imagem importante, quando se sabe o valor do marketing territorial para muitas das decisões socioeconómicas e políticas da actualidade. 
Esta valorização da qualidade ambiental encontra eco na Agenda 21 que se constitui como um poderoso instrumento de reconversão da sociedade industrial rumo a uma sociedade terciária, que exige a "reinterpretação do conceito de progresso, contemplando maior harmonia e equilíbrio global entre o todo e as partes, promovendo a qualidade, não apenas a quantidade do crescimento" (INICIATIVAS DAS AUTORIDADES LOCAIS AGENDA 21).

Com a Agenda 21 criou-se um instrumento aprovado internacionalmente, que tornou possível repensar o planeamento. Abriu-se o caminho capaz de ajudar a construir politicamente as bases de um plano de acção e de um planeamento participativo ao nível global, nacional e local, de forma gradual e negociada, tendo como meta um novo paradigma económico e civilizacional.

O paradigma ecológico parece poder representar esta relação de compromisso. Sabemos que o Homem se afasta da Natureza ao longo do século XX: domina-a com a máquina, manipula-a, explora-a e esquece-se dos sinais. Este é um risco maior que temos que colocar na agenda para a sustentabilidade da vida na Terra. E os pormenores são importantes, como afirma Lorenz (1963). Factores insignificantes podem amplificar-se temporalmente de forma a mudar radicalmente um estado/situação (global). A sustentabilidade urbana ganha uma projecção extraordinária com a Conferência Europeia sobre Cidades Sustentáveis, realizada em Aalborg, na Dinamarca, a 27 de Maio de 1994.

A crise do paradigma moderno baseado na tecnologia veio a valorizar um novo modo de relação entre o homem e a natureza (valorizando o espaço e a sociedade de uma nova forma) através do esbater de um conjunto de oposições: entre a natureza e o homem, entre o local e o total, entre o homem e a sociedade, entre a ciência e o senso-comum.

Não há homem que não seja natural, nem natureza que não seja humana (ANDRÉ, 1996). Tendo por base a consciência do desenvolvimento desigual actual e a previsibilidade da sua ampliação futura e o reconhecimento dos problemas ambientais, as "cidades desempenham um papel essencial no processo evolutivo dos hábitos de vida, da produção, do consumo e das estruturas ambientais" (CARTA DAS CIDADES EUROPEIAS SUSTENTÁVEIS, 1994)

A grande importância desta Carta (1994) é o reconhecimento da capacidade da cidade para a resolução de problemas e não a entender apenas como criadora de dificuldades e impactes negativos. A valorização do capital natural é fundamental em todo este processo (água, solos, energias renováveis, criação de espaço verdes e recreativos, edifícios energicamente eficientes, transportes urbanos ecológicos, responsabilidade pelo clima mundial, prevenção da intoxicação dos ecossistemas), procurando afastar o problema do aquecimento global.

No mesmo sentido, mantêm-se os princípios do protagonismo e envolvimento da comunidade e da qualidade da gestão urbana no sentido da sustentabilidade.

O Plano de Acção de Lisboa: da Carta à Acção veio revitalizar o Guia de Planeamento da

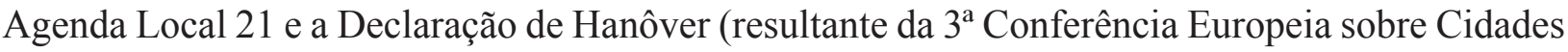
Sustentáveis) permitiu efectuar a avaliação dos percursos das cidades rumo à sustentabilidade.

Todos estes pressupostos de sustentabilidade associados à cidade e à gestão urbana mantêm uma actualidade pungente na procura de um futuro sustentável através de diversas acções e realizações no sentido da preservação da uma boa qualidade de vida a todos os cidadãos e da promoção da sua participação em todos os aspectos relativos à vida urbana. "Desde a Cimeira do Rio, em 1992, e a adopção, em 1994, dos princípios de sustentabilidade explicitados na Carta das Cidades e Vilas Europeias para a Sustentabilidade - Carta de Aalborg - a nossa perspectiva desenvolveu-se através do plano de Acção de Lisboa "Da Carta à Acção, de 1996, da Declaração de Hanôver dos Presidentes de Municípios Europeus "Na viragem para o século XXI", de 2000 e da "Declaração de Joanesburgo, de 2002" (Inspirando o Futuro - Aalborg +10, 2004).

Salientam-se compromissos diversos em que a governância, a gestão local para a sustentabilidade (planeamento, implementação, avaliação); o acesso a bens comuns naturais (acesso equitativo), consumo responsável e opções de estilo de vida, planeamento e desenho urbano, procura de melhor mobilidade associada a menos tráfego, o bem-estar dos cidadãos através de cidades saudáveis), 
o dinamismo económico e sustentável (reforço do emprego), equidade e justiça social (solidariedade), a integração das políticas globais nas realidades locais, enquanto aspectos importantes da sustentabilidade urbana.

A juntar a todas estas realizações temos ainda a Carta de Leipzig das Cidades Europeias Sustentáveis, realizada em 2 de Maio de 2007. Há que salientar o acordo sobre a promoção do estabelecimento de uma organização territorial equilibrada baseada numa estrutura urbana policêntrica e a valorização integrada e temporalmente consentânea das dimensões do desenvolvimento sustentável através da prosperidade económica, do equilíbrio social, do ambiente saudável, da cultura e saúde e da capacidade institucional.

Em última instância, a concretização de uma cidade de nível sustentável terá como objectivo fundamental o bem-estar da população a longo prazo, o que compreende a satisfação das suas necessidades económicas e materiais, mas também as de ordem cultural, social e ambiental, assentes em três ideias básicas: a competitividade económica, a justiça social e a sustentabilidade ambiental.

Alguns projectos tornaram-se o suporte desta sustentabilidade que pode ser exemplificada com alguns casos concretos: a Rede Portuguesa de Cidades e Vilas Sustentáveis (Centro Civitas); o International Council for Local Environmental Initiatives (ICLEI) e o CIty-VITAlity-Sustainability - cleaner and better transport in cities (CIVITAS)

A Rede CIVITAS constitui-se como o pólo dinamizador de uma Rede Portuguesa de Cidades e Vilas Sustentáveis, tendo por finalidade promover a circulação de informação e a troca de experiências entre os seus membros, mediante a disponibilização de um conjunto de serviços no contexto da sustentabilidade local (http://civitas.dcea.fct.unl.pt/faqs.php.) e expressa-se no território do modo como é mostrado na Figura 3.

A rede dirige-se principalmente para as Cidades e Vilas que pretendam desenvolver trabalho no contexto da sustentabilidade local, mas encontra-se aberta a todos aqueles que desejam partilhar experiências e conhecimentos.

Actualmente são cerca de 44 os membros e amigos da rede Civitas. A actividade do Civitas não se estende apenas aos membros da sua rede, realizando projectos em muitos outros municípios do país.

Todavia, um outro Projecto denominado Civitas ganha vida na abordagem da sustentabilidade urbana europeia. As Civitas Cities procuram valorizar um "clear and better transport in cities". Este objectivo é conseguido através de um conjunto de Projectos resultantes da cooperação e parceira entre diversas cidades do grupo.

As propostas genéricas implicam investimento em: energias e veículos ecológicos, acessos condicionados a partes das cidades, estratégias integradas de preços de transportes, redução do estilo de vida automobilizado, ordenamento dos transportes, transporte de bens urbanos e transportes colectivos

Integram um número crescente de cidades europeias que procuram atingir, através de redes de sinergia/inovação, níveis de sustentabilidade adequados à melhoria da qualidade de vida das suas populações.

O Programa Civitas é coordenado por cidades: é um programa de cidades para cidades. As cidades são o centro do partenariado local público/privado, sendo o envolvimento politico um requerimento básico. As cidades são laboratórios vivos para aprender e avaliar.

Apesar de apenas um número limitado de cidades terem sido identificadas como cidades demonstração no Programa Iniciativa Civitas, Civitas mantém-se aberta a participação de outras cidades no Fórum Civitas. Com o início de um no Programa Civitas, mais de 100 cidades que estavam envolvidas em transportes urbanos limpos/ecológicos assinaram a Declaração Civitas, no sentido de Promover e implementar medidas que tornem mais eficientes os transportes urbanos, através de energias limpas e sustentáveis, implementar pacotes integrados de medidas tecnológicas e políticas no campo das energias de transporte e construir um mercado e densidade relacional para a inovação. 


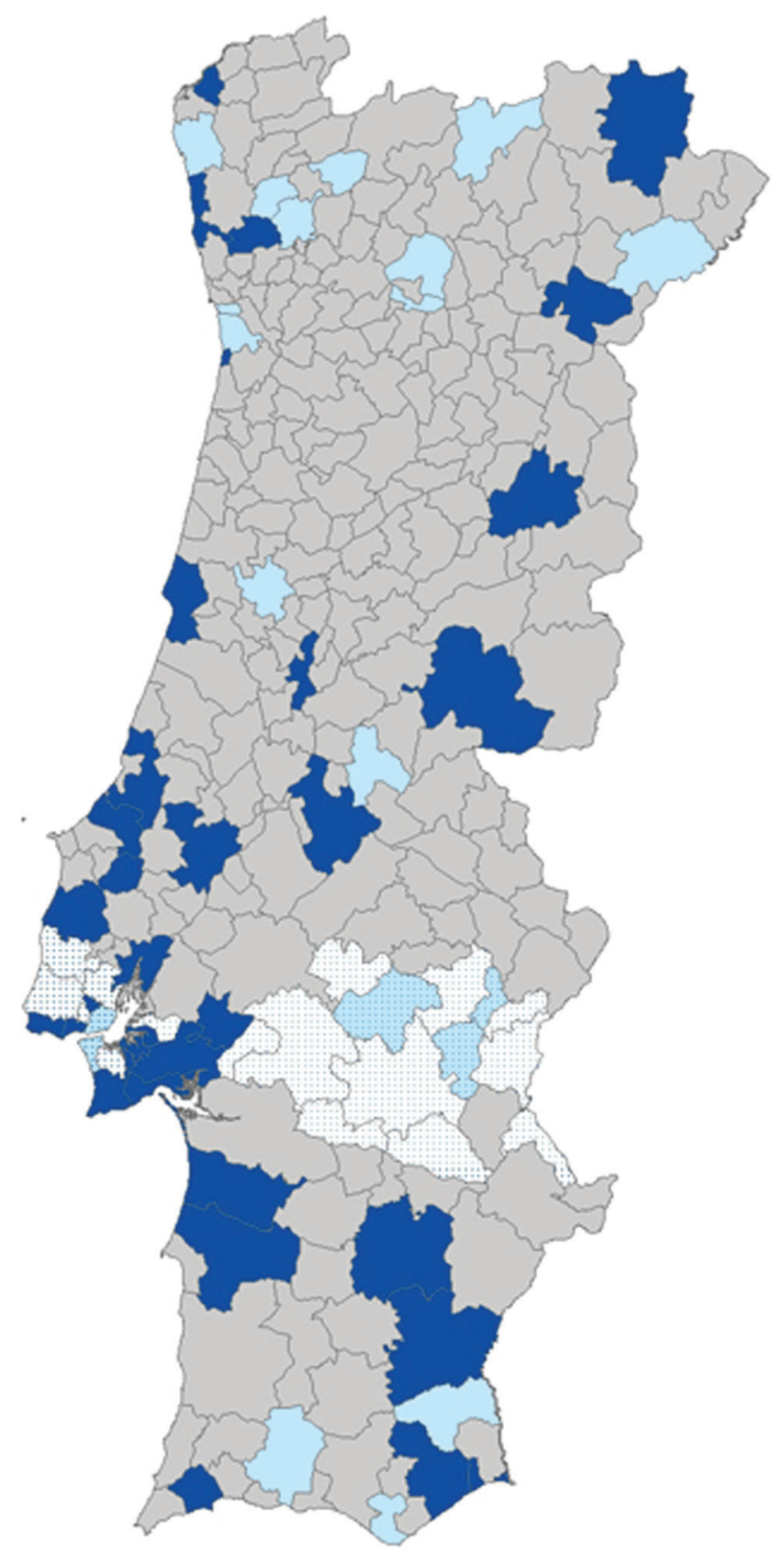

Figura 3 - Rede Civitas

Fonte: http://civitas.dcea.fct.unl.pt/rede.php

Por seu lado, o International Council for Local Environmental Initiatives. (ICLEI) foi fundado em 1990 e é uma Associação internacional de Governos Locais e Organizações Governamentais Regionais com o compromisso do desenvolvimento sustentável. Mais de 550 cidades e suas associações fazem parte do ICLEI (Figura 4), que trabalha com estes e com centenas de outros governos locais fornecendo consultadoria técnica, formação, serviços informativos, para aumentar a capacidade, partilhar conhecimento e promover a implementação do desenvolvimento sustentável ao nível local. 


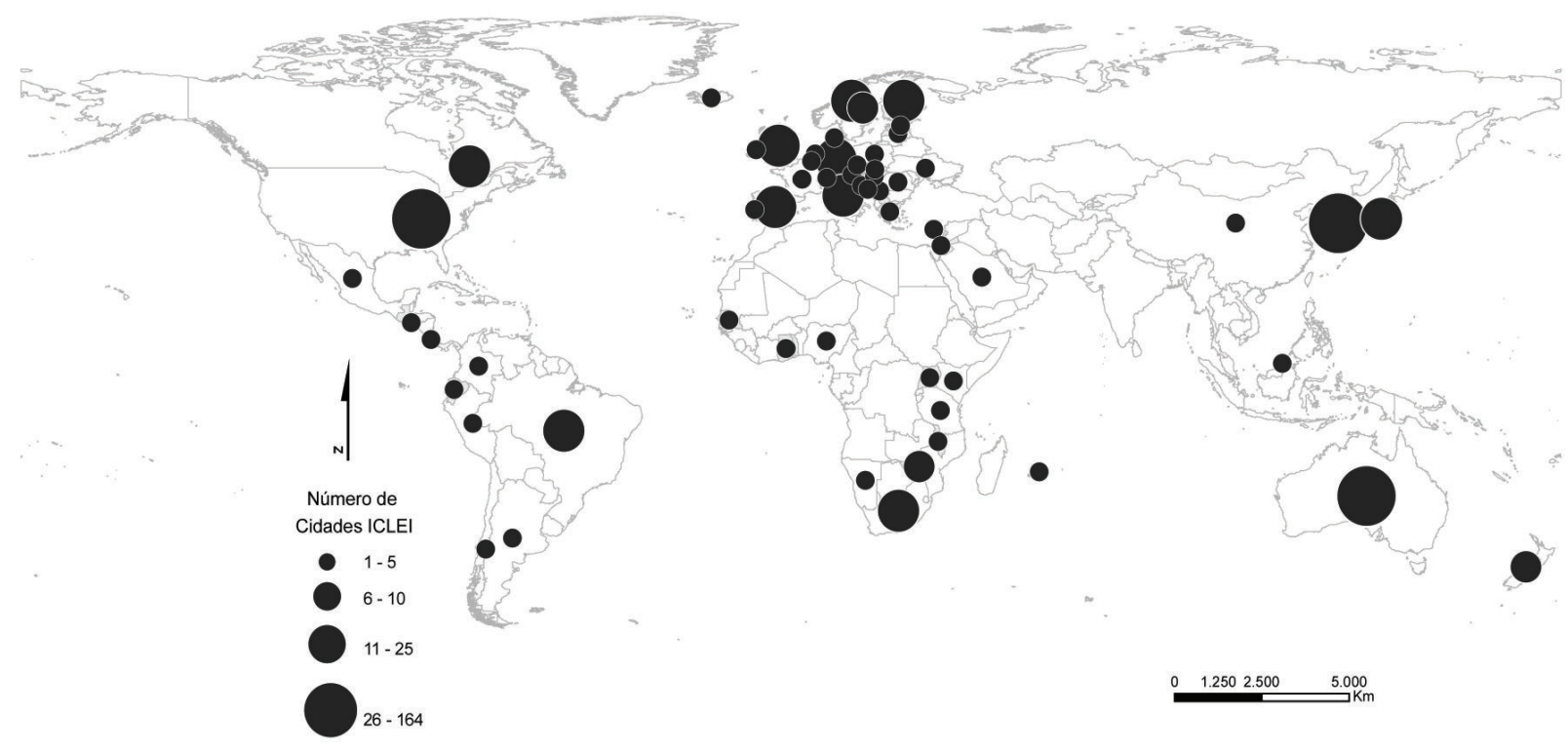

Figura 4 - Rede de cidades ICLEI, por país (2006). Fonte: International Council for Local Environmental Initiatives http://www.iclei.org/

Precisamos de saber como podemos ter competitividade económica promovendo a sustentabilidade ambiental.

Assim, a qualidade de vida e o bem-estar são as pedras de toque de todo o processo de sustentabilidade associada aos espaços urbanos, sendo visível a importância da participação dos cidadãos na identificação dos problemas e mesmo na sua solução, através de métodos mais ou menos directos.

\section{A QUALIDADE DE VIDA}

Tudo se estrutura em torno do propósito de conseguir que a relação das pessoas com o espaço resultem no máximo de qualidade, sabendo que esta só pode ser atingida com a preservação do ambiente e a protecção dos ecossistemas.

Assim, a qualidade de vida e o bem-estar são as pedras de toque de todo o processo de sustentabilidade associada aos espaços urbanos, sendo visível a importância da participação dos cidadãos na identificação dos problemas e mesmo na sua solução, através de métodos mais ou menos directos. Todavia, precisamos de encontrar a qualidade de vida e o bem-estar sem lesar o ambiente

Três âmbitos de análise relativos à qualidade de vida: um primeiro, tem a ver com a distinção entre os aspectos materiais (física e infraestrutural) e imateriais (ambiente, ao património cultural, ao bem estar) da qualidade de vida; um segundo âmbito, faz a distinção entre os aspectos individuais (condição económica, a condição pessoal e familiar) e os colectivos (serviços básicos e os serviços públicos); um terceiro, tem a ver com a distinção entre aspectos objectivos (indicadores de natureza quantitativa) e subjectivos (percepção) da qualidade de vida. (SANTO; MARTINS, 2002)

Em muitos dos trabalhos sobre a qualidade de vida a abordagem desenvolvida é orientada para o estabelecimento de rankings. Melhores cidades para se viver, apresentando hierarquias que envolvem conjuntos mais ou menos alargados de centros urbanos, geralmente vocacionados para apoiar decisões de relocalização de residência ou de investimentos.

À escala nacional José Mendes (1999) estuda a qualidade de vida nas cidades capitais de distrito, através da utilização dos parâmetros poluição, habitação, desemprego, criminalidade, comércio e serviços, mobilidade, poder de compra, património e clima. Alguns meses depois o Diário de Notícias (2000), elabora um estudo sobra "As melhores Cidades Portuguesas", (áreas urbanas 
com mais de vinte mil habitantes e todas as capitais de distrito, à excepção de Lisboa e Porto); e “A Vida nas Áreas Metropolitanas", que se revela muito interessante e mostra a importância deste tipo de avaliação para os territórios.

Tal como noutros países é preciso tornar os estudos dinâmicos, mantendo um sistema de indicadores que permita a comparação de resultados entre estratégias locais de intervenção e recolha e tratamento de dados que sejam sistemáticas, no sentido da monitorização.

Não existe uma só qualidade de vida. Existem variações de qualidade que determinam uma maior ou menos qualidade de vida urbana, entrecruzando-se com a noção de classe socioespacial de Alain Reynaud (1981). Todavia, a avaliação da qualidade de vida numa cidade é marcada pela subjectividade, devido ao seu carácter multidimensional, mas também pelas diferenciações espaciais. Deste modo, apesar de se avaliar a qualidade de vida de uma cidade no seu todo, uma perspectiva mais localizada dessa avaliação contribuiria para que a identificação de problemas e as estratégias de remediação fossem mais eficazes (VALENTE, 2006).

É importante valorizar a cidade na sustentabilidade propondo a tentativa de fazer com que haja um compromisso entre crescimento económico e desenvolvimento sustentável, aproximando as cidades dos cidadãos, porque, em Portugal, o planeamento faz-se, com demasiada frequência, à revelia dos cidadãos.

\section{CONSIDERAÇÕES FINAIS}

De acordo com Blowers e Young (2000) as políticas têm que promover uma maior equidade social, condição essencial para a coesão social necessária para assegurar a transformação em direcção à sustentabilidade.

O desenvolvimento urbano sustentável necessita de ser planeado a longo termo. Requer um sistema de planeamento integrado e estratégico relacionando critérios sociais e físicos ao nível global, nacional e local.

É necessária uma liderança forte a nível nacional para promoção de políticas que sejam relevantes para as escalas dos problemas e adequadamente suportadas

A mudança das actuais cidades insustentáveis para as cidades sustentáveis do amanhã não tomará lugar a não ser que haja mudanças fundamentais na sociedade que influenciem e respondam às mudanças políticas. Um desenvolvimento sustentável marcante só pode ser obtido através da transformação social.

É difícil perceber como pode isso acontecer porque os valores que nos levaram às cidades insustentáveis estão profundamente implantados nas estruturas que orientam a sociedade contemporânea. O planeamento do desenvolvimento sustentável requer uma abordagem holística que transcende os sectores político-económicos e envolve critérios sociais e também os ambientais. Implica nova legislação e uma mudança cultural que coloque a sustentabilidade ambiental e a equidade social no centro do processo de desenvolvimento urbano. (BLOWERS; YOUNG - 2000)

Embora tenhamos valorizado um conjunto de aspectos positivos que têm tomado lugar nas últimas décadas, sendo as propostas de sustentabilidade ecológica para a cidade muito louváveis, o intuito de se tornarem uma norma global parece ser um objectivo distante. As forças económicas actuais para além do controlo de qualquer processo de consciência humana estão a trabalhar precisamente na direcção oposta. Um mundo de cidades individuais, grandemente constrangidas nas suas fronteiras geográficas, competindo pelo crescimento (definido apenas como actividades de negócios) no quadro de um mercado global, não parece ser capaz de atingir uma sustentabilidade ecológica (GLEESON; LOW, 2000).

A importância da sustentabilidade e do nível de intervenção local são centrais para a qualidade de vida e para o desenvolvimento. Suporte para a vida e para o vivido, o espaço é também percebido e representado, assim como simbólico e de ordenamento ao ser utilizado como instrumento político (SANTOS et al., 2010). É necessário tomar em consideração a conjugação das dimensões 
económica (eficiência, crescimento, estabilidade), social (equidade, solidariedade) e ecológica (reprodutibilidade dos recursos naturais) (MELA et al., 2001, p. 21 e 22), de forma a conseguir intervenções equilibradas e eficazes.

\begin{tabular}{|c|c|}
\hline $\begin{array}{l}\text { Características } \\
\text { Socioeconómicas }\end{array}$ & $\begin{array}{c}\text { Preservação } \\
\text { Ambiental }\end{array}$ \\
\hline $\begin{array}{l}\text { Recursos humanos } \\
\text { Gestão de equipamentos } \\
\text { Hospitalidade }\end{array}$ & $\begin{array}{r}\text { Gestão de riscos } \\
\text { Gestão de recursos físicos } \\
\text { Ecoturismo }\end{array}$ \\
\hline \multicolumn{2}{|c|}{$\begin{array}{c}\text { Sustentabilidade territorial } \\
\text { Lazer/Desenvolvimento } \\
\text { Urbano/Rural } \\
\text { Acessibilidades } \\
\text { Centro/Periferia } \\
\text { Planeamento/Gestão } \\
\text { Ordenamento }\end{array}$} \\
\hline $\begin{array}{l}\text { Planeamento participativo } \\
\text { Políticas Locais } \\
\text { Representatividade e Participação }\end{array}$ & $\begin{array}{r}\text { Património } \\
\text { Identidade territorial } \\
\text { Eventos e Marketing }\end{array}$ \\
\hline Decisões & Expressã \\
\hline Políticas & Simbólic \\
\hline
\end{tabular}

Figura 5 - Parâmetros de avaliação da sustentabilidade territorial Fonte: (SANTOS et al., 2010)

Como afirmámos em Santos et. al. (2010) a importância da sustentabilidade, implica que o elemento ecológico seja expresso em modos de gestão suportados por intervenções que assegurem a qualidade de vida e a boa gestão dos suportes físicos para o desenvolvimento. É preciso, contudo, colocar nesta equação também a actuação política e a expressão simbólica e imagem dos lugares, individualizando a importância das políticas adoptadas, com vista ao desenvolvimento local, dando significado à representatividade e à participação dos grupos de interesse, enquanto parceiros na actuação para o desenvolvimento. Ainda assim, importa salientar a importância da capacidade de transmitir uma imagem com uma identidade própria, capaz de cativar a atenção e a acção de externalidades diversas, baseada na inovação, na tradição, na organização e/ou no espectáculo. Dá-se assim expressão às mobilidades, às acessibilidades e às relações entre diversos modos de organização do espaço (homogéneos ou diferenciados) através de intervenções capazes de valorizar a coesão territorial.

\section{REFERÊNCIA BIBLIOGRÁFICA}

ANDRADE, Liza M. S. O conceito de Cidades-Jardins: uma adaptação para as cidades sustentáveis. Arquitextos, 42.02, Ano 4, 2003, http://www.vitruvius.com.br/arquitextos/arq042/arq042_02.asp (Consultado em Junho de 2011)

ASCHER, François. Metapolis, acerca do futuro da cidade. Oeiras: Celta: 1998.

ATLAS DAS CIDADES DE PORTUGAL. Lisboa: Instituto Nacional de Estatística, 2002.

BIMONT, G. Les facettes de la rationalité. Sciences Humaines no 66, Novembro, Auxerre, 1996, p 12-13. BLOWERS, Andrew; YOUNG, Stephen. Britain: unsustainable cities. In: Nicholas Low et al. Consuming Cities. The urban Environment in the Global Economy after the Rio Declaration. Londres:.Routledge, Taylor and Francis, 2000, p. 1-29.

CAMAGNI, Roberto. Príncipes et modeles de l'économie urbaine. Paris: Association de Science Régionale de Langue Française, Biblioteque de Science Régionale, Económica, 1992. 
CAMPANHA EUROPEIA DE CIDADES E VILAS SUSTENTÁVEIS - Conferência Aalborg+10 Inspirando o Futuro, Tradução Prof. João Farinha e Dr. ${ }^{a}$ Lurdes Poeira, http://www.anmp.pt/anmp/div2005/ age21/docs/a22.pdf, 2004.

CARTA DE AALBORG. Carta das cidades europeias para a sustentabilidade (aprovada pelos participantes na Conferência Europeia sobre Cidades Sustentáveis, Aalborg, Dinamarca, 27 de Maio de 1994, 2004, http://www.futurosustentavel.org/gca/?id=11 (Consultado em Maio de 2011)

CARTA DE LIEPZIG SOBRE CIDADES EUROPEIAS SUSTENTÁVEIS (2007) http://www.forumdourbanismo.info/index.php

CIty-VITAlity Sustainability - cleaner and better transport in cities (CIVITAS), http://www.civitas-initiative. org/ (Consultado em Junho de 2011)

COMISSÃO MUNDIAL PARA O AMBIENTE E DESENVOLVIMENTO. O nosso futuro. Uma terra um mundo: o testemunho da Comissão Mundial para o Ambiente e Desenvolvimento, Gabinete de Estudos e Planeamento da Administração do Território, 2ª ed., Lisboa, 1989.

CONFERÊNCIA DAS NAÇÕES UNIDAS SOBRE MEIO AMBIENTE E DESENVOLVIMENTO, Agenda 21, Capítulo 28, Ponto 3 - Iniciativas das Autoridades Locais em Apoio à Agenda 21 (Área de Programas). Rio De Janeiro, 3 - 14 de Junho De 1992, http://www.agenda21local.info/index.php (Consultado em Junho de 2011)

CONFERÊNCIA DAS NAÇÕES UNIDAS SOBRE O MEIO AMBIENTE E DESENVOLVIMENTO, Rio de Janeiro, 1992, http://www.agenda21local.info/index.php (Consultado em Maio de 2011) e http://www. diramb.gov.pt/data/basedoc/TXT_LI_6180_1_0001.htm (Consultado em Junho de 2011)

DECLARAÇÃO DE HANÔVER. Na viragem para o século XXI, Terceira Conferência Europeia sobre Cidades Sustentáveis, dos Presidentes de Municípios Europeus, Hanôver, 2000.

DECLARAÇÃO DE JOANESBURGO SOBRE DESENVOLVIMENTO SUSTENTÁVEL. Cúpula Mundial sobre Desenvolvimento Sustentável, Joanesburgo, 2002.

DECO PROTESTE ON-LINE. Qualidade de vida, num inquérito em 76 cidades europeias (Junho de 2007), http://www.deco.proteste.pt/ (Consultado em Junho de 2011), 2007.

DI MÉO, Guy. Géographie Sociale et Territoires. Paris: Nathan, 1998.

DIÁRIO DE NOTÍCIAS. A Vida nas Áreas Metropolitanas, Edições de 15 a 22 de Julho, 2000.

DIÁRIO DE NOTÍCIAS. As Melhores Cidades Portuguesas, Edições de 5 a 11 de Fevereiro, 200.

DIRECÇÃO-GERAL DO ORDENAMENTO DO TERRITORIO E DESENVOLVIMENTO URBANO (DGOTDU) http://www.dgotdu.pt/.

FERRÃO, João. Dinâmicas demográficas: Uma visão panorâmica. Parte II, População e Território. In: Carlos Alberto Medeiros (Dir.). Geografia de Portugal. Rio de Mouro: Circulo de Leitores, 2005. p. 50-71.

FÓRUM DO URBANISMO - Cooperação Europeia nos domínios da Coesão Territorial e do Desenvolvimento Urbano - 16.06.07) http://www.forumdourbanismo.info/index.php

GLEESON, Brendan e LOW, Nicholas. Cities as consumers of the world's environment. In: Nicholas Low et al. Consuming Cities. The urban Environment in the Global Economy after the Rio Declaration, Londres: Routledge, Taylor and Francis, 2000. p. 1-29.

GRUPO DE PERITOS SOBRE O AMBIENTE URBANO DA COMISSÃO EUROPEIA. Comissão Europeia, Direcção Geral XI, Ambiente, Segurança Nuclear e Proteç̧ão Civil, Bruxelas, (Consultado em Julho de 2011), 1996, http://ec.europa.eu/environment/urban/pdf/exsum-pt.pdf

LEIDENBERGER, Georg Nature and the public: Urban ecology and the politics of transportation in Progressive - Era Chicago. Revista de Urbanismo, 3, Departamento de Urbanismo, Facultad de Arquitectura y Urbanismo de la Universidad de Chile, 2000, (http://revistaurbanismo.uchile.cl/). (Consultado em Maio de 2011)

LORENZ, Edward N. Deterministic Non-periodic Flow. Journal of the Atmospheric Sciences, Volume 20, nº 2, American Meteorological Society, Boston, Massachusetts, 1963, p 130-141.

MELA, Alfredo; BELLONI, Maria Carmen; DAVICO, Luca. A sociologia do ambiente. Lisboa: Editorial Estampa, 2002. 
MENDES, José. Onde viver em Portugal : uma análise da qualidade de vida nas capitais de distrito. Ordem dos Engenheiros - Região Centro, Coimbra, 1999,1 134 pp.

PLANO DE ACÇÃO DE LISBOA. Da Carta à Acção, Segunda Conferência Europeia das Cidades e Vilas Sustentáveis, 6 e 8 de Outubro, Lisboa, 1996, http://www.futurosustentavel.org/gca/?id=11 (Consultado em Maio de 2011)

REDE PORTUGUESA DE CIDADES E VILAS SUSTENTÁVEIS (Centro Civitas); http://civitas.dcea.fct. unl.pt/rede.php (Consultado em Junho de 2011)

REYNAUD, Alain. Société, espace et justice: inégalités régionales et justice socio-spatiale. Paris: PUF, 1981. SANTOS, L. D. e MARTINS, I. A qualidade de vida urbana. O caso da cidade do Porto. Investigação Trabalhos em curso - ${ }^{\circ}$ 116, Maio, Working Papers da FEP, Faculdade de Economia, Universidade de Porto, Porto, 2002, 24 pp.

SANTOS, Lusitano. Planos de Urbanização para a Cidade de Coimbra. Museu Nacional machado de Castro, Coimbra, 1983, 95 pp.

SANTOS, Sandro. Coimbra: expansão urbana e acessibilidades. Tese de Mestrado Geografia, Geografia Humana - Território e Desenvolvimento, apresentada à Faculdade de Letras da Universidade de Coimbra, Coimbra, 2005, 353pp. (policopiado).

SANTOS, Norberto; CRAVIDÃO; Fernanda; CUNHA, Lúcio. Natureza, paisagens culturais e os produtos turísticos associados ao território, Actas (CD) 4to Congresso Latinoamericano de Investigación Turística, Universidad de la República Oriental del Uruguay, Montevideo, 2010, 26 pp.

SZMRECSÁNYI, T. e FERNANDES, F. Malthus, Colecção Grandes Cientistas Sociais, Economia. São Paulo: Editora Ática, 1982.

TAVARES, Alexandre Oliveira e CUNHA, Lúcio. Perigosidade natural na gestão territorial. O caso do Município de Coimbra. In: Callapez, Pedro Miguel (ed.). A terra: conflitos e ordem: homenagem ao Professor Ferreira Soares. Coimbra: 2008, p. 89-100.

VALENTE, Prudência. Qualidade de vida urbana. A cidade da Guarda. Dissertação de Mestrado, espacialidade em Educação Ambiental, apresentada à Faculdade de Letras da Universidade de Coimbra, Coimbra, 2006.

VINHA, Luís. Planta de Zonamento do Plano DeGroer, 2004.

Sites Consultados

http://www.agenda21local.info/index.php (Consultado em Junho de 2011)

http://www.diramb.gov.pt/data/basedoc/TXT_LI_6180_1_0001.htm (Consultado em Junho de 2011)

http://www.ecologicalfootprint.org/ - Ecological Footprint Organization - Redefining Progress (Consultado em Junho de 2011)

http://www.esb.ucp.pt/gea/myfiles/pegada/pegada.htm. (Consultado em Junho de 2011)

http://www.forumdourbanismo.info/index.php (Consultado em Junho de 2011)

http://www.pime.org.br/mundoemissao/estatisticasmundo2.htm. (Consultado em Junho de 2011)

http://www.qren.pt/ (Consultado em Junho de 2011)

http://www.unhabitat.org/. (Consultado em Junho de 2011)

International Council for Local Environmental Initiatives (ICLEI) - http://www.iclei.org/ (Consultado em Junho de 2011) 